\title{
Solutions to gather and transport crude oil from Dai Hung Nam wellhead platform (WHP-DHN) to FPU DH-01 platform at Dai Hung Oil Field
}

\author{
Thinh Van Nguyen ${ }^{1,}$, Dong Van Tang ${ }^{2}$, Duyen Quang Le ${ }^{1}$, Vinh The Nguyen ${ }^{1}$ \\ ${ }^{1}$ Faculty of Oil and Gas, Hanoi University of Mining and Geology, Vietnam \\ ${ }^{2}$ Dai Hung Oilfield, PetroVietnam Exploration Production Corporation (PVEP), Vietnam
}

\section{ARTICLE INFO}

Article history:

Received $12^{\text {th }}$ Nov 2019

Revised 26th Jan. 2020

Accepted 28 ${ }^{\text {th }}$ Feb. 2020

\section{Keywords:}

Flow assurance,

Oil and gas transportation

pipelines,

Dai Hung oil field.

\section{ABSTRACT}

Dai Hung is an oilfield which lies at a deep water. The field is located in the Northeast of Nam Con Son basin in block 05-1a. The total production explored at Dai Hung in April 30, 2018 reached 56.7 million barrels, corresponding to 13\% of the average recovery coefficient of the oil field. The success of drilling wells for the development of Phase II (WHP-DH2) has proved that oil and gas exploitation in areas without drilling wells at Dai Hung oi field is potential. At present, PetroVietnam Exploration Production Corporation (PVEP) keeps undertaking activities on drilling exploration wells at Dai Hung Nam zone with positive results. This fact requires the construction of the offshore platform at this area for oil and gas exploitation activities. Therefore, Dai Hung Nam wellhead platform (WHP-DHN) will be built in this area and its exploited products will be transported to DH-01 platform by subsea pipelines. In order to transport exploited products safety, a research on flow assurance is required to consider and evaluate possibilities that may have effect on transportation process. The paper presents the results of research on hydraulic calculations for subsea pipelines to transport exploited products from WHP-DHN to DH-01 platform by taking advantage of experimental equations and using the software with the data obtained at this Oil Field. The results of the research will be the basic which helps to select the appropriate solutions to improve the transportation of exploited productions by subsea pipelines at WHPDHN in the future stage.

Copyright (C) 2020 Hanoi University of Mining and Geology. All rights reserved.

${ }^{*}$ Corresponding author

E-mail: nguyenvanthinh@humg.edu.vn

DOI: 10.46326/JMES.2020.61(1).07 


\title{
Tạp chí Khoa học Kỹ thuật Mỏ - Địa chất
}

Trang điện tử: http://tapchi.humg.edu.vn

\section{Nghiên cứu giải pháp thu gom vận chuyển dầu từ giàn Đại Hùng Nam (WHP - DHN) về giàn FPU DH - 01 mỏ Đại Hùng}

\author{
Nguyễn Văn Thịnh ${ }^{1}{ }^{*}$, Tăng Văn Đồng ${ }^{2}$, Lê Quang Duyến ${ }^{1}$, Nguyễn Thế Vinh ${ }^{1}$ \\ ${ }^{1}$ Khoa Dầu khí, Trường Đại học Mỏ - Địa chất, Việt Nam \\ ${ }^{2}$ Mỏ Đại Hùng, Tổng Công ty Thăm dò Khai thác Dầu khí (PVEP), Việt Nam
}

\section{THÔNG TIN BÀI BÁO \\ TÓM TẮT}

Quá trình:

Nhận bài $12 / 11 / 2019$

Sứa xong 26/01/2020

Chấp nhận đăng 28/02/2020

Tù khóa:

Đảm bảo dòng chảy, Đường ống vận chuyển dầu,

Mỏ Đại Hùng.
Đại Hùng là một mỏ dầu khí nằm ở vùng nước sâu, phía Đông Bắc bồn trũng Nam Côn Sơn, thuộc Lô 05 - 1a. Tính đến thời điểm 30/04/2018, tổng sản lượng dầu khai thác toàn mỏ đạt 56,7 triệu thùng, tương úng với 13\% hệ số thu hồi trung bình toàn mỏ. Thành công từ các giếng khoan phát triển mỏ Pha II (WHP - DH2) đã khẳng định tiềm năng dầu khí trong khu vực mỏ Đại Hùng ở những khối chưa có giếng khoan là rất khả quan. Hiện nay Tổng công ty Thăm dò Khai thác dầu khí đang tiếp tục cho tiến hành phát triên các hoạt động khoan giếng thăm dò cụm cấu tạo Đại Hùng Nam và đã cho kết quả rất khả quan. Do đó, việc xây dựng các cổng trình thuộc khu vực này để phục vự hoạt động khai thác dầu khí là rất cần thiết, giàn Đại Hùng Nam (WHP - DHN) sẽ được xây dựng trên khu vực này. Sản phẩm khai thác sẽ được vận chuyến về giàn Đại Hùng - 01 (ĐH - 01) bằng đường ống ngầm. Để quá trình vận chuyển sản phẩm đảm bảo an toàn cần có các nghiên cứu đảm bảo dòng chảy để xem xét đánh giá, dự đoán các khả năng có thể xảy ra làm ảnh hương đến quá trình vận chuyển. Bài báo trình bày các kết quả nghiên cúu về các tính toán thủy lực cho tuyến đường ống thu gom, vận chuyển sản phẩm tù̀ giàn WHP - DHN về giàn $Đ H$ - 01 dựa trên các phương trình thực nghiệm và sử dụng phần mềm mô phỏng tù̀ số liệu thực tế. Kết quả nghiên cúu sẽ là cơ sở để lựa chọn phương án tối ưu cho quá trình vận chuyển sản phẩm tại khu vực Đại Hùng Nam trong giai đoạn hiện nay.

(C) 2020 Trường Đại học Mỏ - Địa chất. Tất cả các quyền được bảo đảm.

\section{Mở đầu}

Mỏ dầu khí Đại Hùng nằm ở phía Đông Bắc bồn trũng Nam Côn Sơn, thuộc lô 05 - 1a. Hiện nay mỏ Đại Hùng (DH) đang được điều hành bởi Tổng

*Tác giả liên hệ

E - mail: nguyenvanthinh@humg. edu.vn

DOI: 10.46326/JMES.2020.61(1).07
Công ty Thăm dò và Khai thác Dầu khí (PVEP). Hệ thống thiết bị khai thác sớm của mỏ Đại Hùng bao gồm hệ thống sản xuất nổi FPU (Floating Productions Unit) và hệ thống tàu chứa FSO - Phao CALM. Các giếng được hoàn thiện là giếng ngầm, dầu khai thác từ các đầu giếng ngầm chảy theo hệ thống ống mềm, qua phao ngầm về phía mạn phải giàn FPU DH - 01. Sau khi dầu qua hệ thống xử lý được bơm qua hai đường ống xuất ngầm dưới biển sang phao CALM và từ phao CALM theo 
đường ống xuất nổi sang tàu chứa FSO (Nguyễn Văn Thịnh et al., 2018). Hiện nay mỏ Đại Hùng đã đi vào khai thác được 25 năm, sản lượng khai thác đang trong giai đoạn suy giảm, một số giếng phải đóng, số còn lại chỉ khai thác theo chu kỳ. Trước những khó khăn đó, để có thể tiếp tục duy trì hoạt động dầu khí tại mỏ Đại Hùng, cần phải tiến hành các nghiên cứu chi tiết hơn về mô hình địa chất mỏ Đại Hùng, làm cơ sở cho việc phát triển mở rộng Mỏ. Dựa trên các kết quả nghiên cứu bổ sung này, mỏ Đại Hùng đã được phê duyệt để mở rộng về khu vực phía Nam. Theo đó, trong giai đoạn 2 của mỏ, giàn đầu giếng WHP - DH2 (nằm cách giàn FPU DH - 01khoảng $5 \mathrm{~km}$ về phía Tây $\mathrm{Nam}$ ), đã được đưa vào vận hành 08/2011 với lưu lượng dầu ban đầu đạt 5.000 thùng/ngày sau đó tăng lên và được duy trì ổn định ở mức 9.000 thùng/ngày. Sản phẩm từ giàn WHP - DH2 được vận chuyển về giàn FPU DH - 01 thông qua đường ống ngầm đường kính 6 inchs. Đến tháng 12/2015 đã chính thức kết nối đường ống thu gom khí từ giàn WHP - DH2 vào đường ống qua giàn $\mathrm{BK}$ - Thiên Ưng về giàn xử lý trung tâm (CPP2) mỏ Bạch Hổ. Tổng sản lượng khai thác tích lũy từ giàn FPU DH - 01 đến thời điểm 30/04/2018 là 39,80 triệu thùng dầu, tương ứng với hệ số thu hồi 15,5\%. Tổng sản lượng khai thác tích lũy từ giàn WHP - DH2 đến thời điểm 30/04/2018 là 16,90 triệu thùng dầu, tương ứng với hệ số thu hồi 9,1\%. Tính đến thời điểm 30/04/2018, tổng sản lượng dầu khai thác toàn mỏ DH đạt 56,7 triệu thùng, tương ứng với hệ số thu hồi trung bình toàn mỏ đạt gần $13 \%$ (Tổng Công ty Thăm dò Khai thác Dầu khí, 2017, 2019).

Từ thành công các giếng khoan phát triển mỏ giai đoạn 2 (WHP - DH2) đã khẳng định tiềm năng dầu khí trong khu vực mỏ Đại Hùng ở những khối chưa có giếng khoan là rất khả quan. Ngoài ra, tham khảo kết quả từ các giếng khoan trong các Lô lân cận như Lô 4 - 3 của Liên doanh Việt - Nga (Vietsovpetro) và Lô $05.1 b \& c$ của Idemitsu cho thấy tiềm năng trên toàn bộ vùng mỏ Đại Hùng có nhiều triển vọng, cần được quan tâm khai thác. Trên cơ sở đó, Tổng Công ty PVEP đã tiến hành khoan giếng thăm dò DHN - $1 \mathrm{~N}$ trên khối A7.1 thuộc cụm cấu tạo Đại Hùng Nam (DHN). Dựa trên các kết quả thăm dò, thẩm lượng cho thấy, cấu tạo DHN đang được xem xét để có thể sớm phát triển đưa vào khai thác cùng với khu vực đang khai thác mỏ Đại Hùng. Hiện nay việc phát triển DHN đang có rất nhiều phương án, một trong số là việc lắp đặt giàn WHP - DHN là giàn không người ở, vận hành từ giàn $\mathrm{FPU} \mathrm{DH}$ - 01, trên giàn có cụm thu gom dòng và bình tách cấp 1 .

Giàn được lắp đặt cố định trên "Existing drilling template" hạn chế đến mức tối đa sự tiếp cận của những thiết bị và phương tiện bên ngoài. Nguồn năng lương, điều khiển được cung cấp và vận hành từ giàn FPU $\mathrm{DH}$ - 01 bằng đường cáp ngầm (Hình 1).

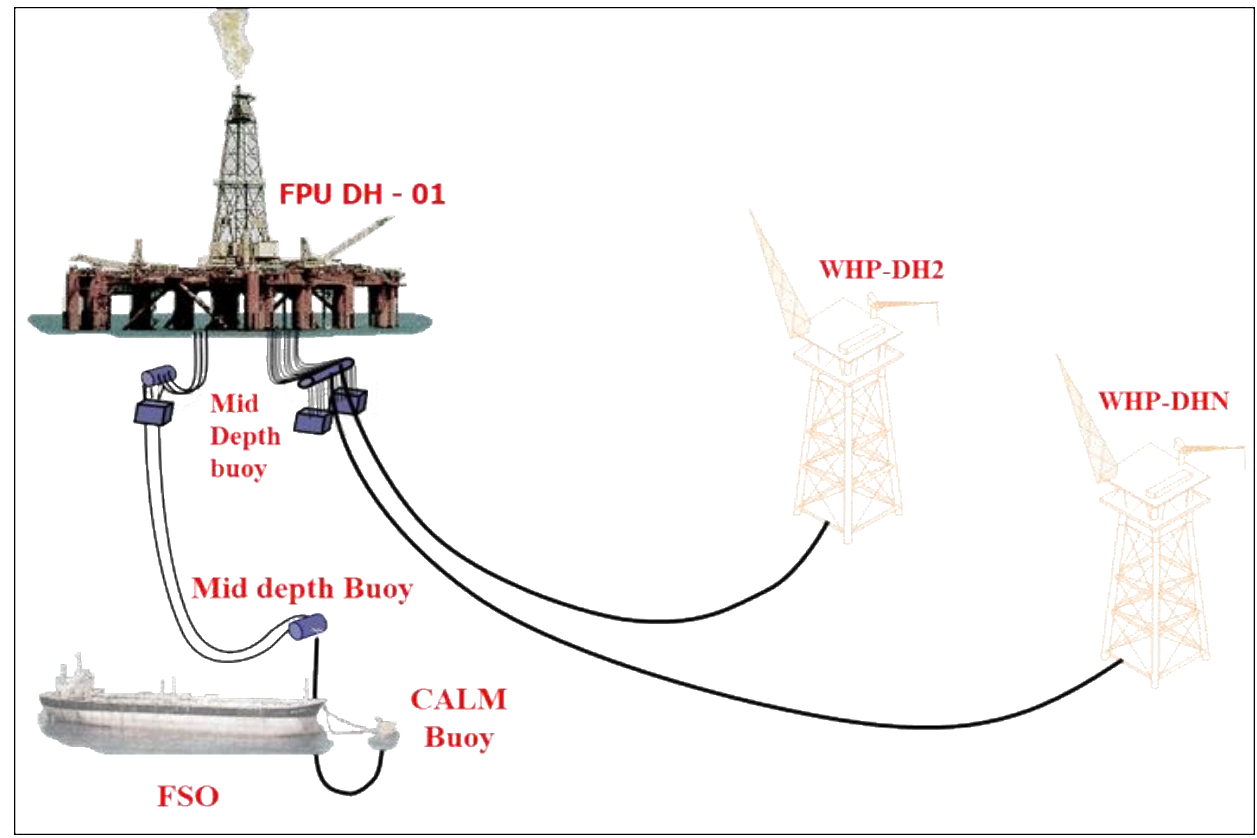

Hình 1. So đồ phát triển giàn WHP - DHN mỏ Đại Hùng (Tổng Công ty Thăm dò Khai thác Dầu khí, 2019). 
Trên WHP - DHN sản phẩm khai thác dự kiến 18.000 thùng/ngày đêm từ các giếng sẽ được tách khí sơ bộ trong bình tách cao áp (HHP separator), dầu bão hoà khí sẽ được vận chuyển bằng áp suất bình tách (không dùng máy bơm) về giàn khai thác FPU DH - 01 để tiếp tục xử lý. Khí tách ra trong bình tách cao áp trên WHP - DHN sẽ được đưa sang WHP - DH2 để xuất đưa về bờ. Dự định trong giai đoạn đầu khí sẽ được đưa cùng dầu về giàn FPU DH - 01 để sử dụng chạy máy phát điện. Chất lỏng sau khi tách trong bình cao áp dưới dạng bão hoà khí sẽ được vận chuyển dưới áp suất bình tách về FPU DH - 01 bằng đường ống ngầm nối từ giàn đầu giếng WHP DHN vắt qua phao trung gian mạn sau lên đến giàn FPU DH - 01. Trên FPU DH - 01, dầu bão hoà khí từ WHP - DHN cùng với hỗn hợp dầu khí khai thác trên các giếng ngầm xung quanh FPU sẽ được tách khí và tách nước sơ bộ trong các bình tách ba pha. Dầu sau khi tách khí và tách nước sơ bộ sẽ được bơm từ giàn FPU DH - 01 qua cụm phao CALM bằng hai đường ống mềm xuất dầu 6inch tới tàu chứa. Khí tách ra trên FPU DH - 01 sẽ được sử dụng để chạy máy phát phần còn lại sẽ chuyển sang hệ thống xuất khí (dự định phát triển trong tương lai) hoặc đốt bỏ tại đuốc trên giàn.

\section{Mô hình hóa và đề xuất giải pháp đảm bảo dòng chảy trong đường ống vận chuyển dâu từ giàn WHP - DHN về giàn FPU DH - 01}

Quá trình nghiên cứu đảm bảo dòng chảy cần phải xem xét đánh giá, dự đoán các khả năng có thể xảy ra trong quá trình vận chuyển với các điều kiện khác nhau phù hợp với hệ thống hiện hữu, để chọn lựa các thông số tối ưu và kinh tế nhất nhằm đảm bảo quá trình vận chuyển an toàn cho hệ thống thiết bị. Để vận chuyển dầu từ WHP - DHN về giàn FPU DH - 01 cần tính toán chọn lựa phương án kết nối, đường kính ống vận chuyển, nghiên cứu đảm bảo dòng chảy phù hợp với các kịch bản sản lượng khai thác từ giàn đầu giếng WHP - DHN, cụ thể như sau:

Tính toán, xác định đường kính tối ưu để vận chuyển dầu với lưu lượng lớn nhất, đảm bảo các thông số áp suất, nhiệt độ đầu vào/ đầu ra nằm trong giới hạn thiết kế của thiết bị khi vận chuyển ổn định (Steady State Flow);

Tính toán xác định chiều dày tối thiểu lớp cách nhiệt của đường ống dẫn dầu với trường hợp sản lượng thấp nhất đảm bảo an toàn cho đường ống khi vận chuyển ổn định (Steady State Flow);

Đánh giá sự tích tụ chất lỏng trong đường ống do địa hình (Terrain Slugging) với các kịch bản sản lượng khác nhau.

\subsection{Tính chất đặc thù của dầu ở mỏ Đại Hùng Nam}

Dầu thô khai thác tại các mỏ ở thềm lục địa Việt Nam nói chung có hàm lượng paraffin và độ nhớt tương đối cao, làm ảnh hưởng đến quá trình thu gom, vận chuyển sản phẩm (Nguyễn Thúc Kháng et al., 2016). Khi hàm lượng paraffin trong dầu cao cùng với điều kiện nhiệt độ thấp sẽ làm cho dầu trở nên kém linh động, gây khó khăn cho quá trình vận chuyển trong đường ống (Aiyejna et al., 2011; Burger et al., 1981). Dầu thô khai thác ở khu vực DHN có hàm lượng paraffin và độ nhớt cao, nhiệt độ đông đặc của dầu là $30^{\circ} \mathrm{C}$, trong khi đó nhiệt độ thấp nhất của vùng cận đáy biển quanh đường ống dao động từ $12 \div 18^{\circ} \mathrm{C}$ tùy theo mùa. Như vậy trong quá trình dừng dòng chảy, nguy cơ dầu đông đặc trong đường ống là rất cao. Nhiệt độ bắt đầu kết tinh của paraffin (Wax Apearance Temparature, WAT), được xác định ở mức 38,3ㄷ. Một trong những cơ sở dữ liệu quan trọng để mô hình hoá các quá trình nhiệt thủy động lực học trong đường ống cũng như quá trình tách khí trong bình tách là thành phần cấu tử của dầu vỉa. Dựa trên dữ liệu thu thập được, có thể tóm tắt một số tính chất lý - hoá của dầu khai thác tại mỏ DHN như sau: Nhiệt độ đông đặc: $30^{\circ} \mathrm{C}$; Nhiệt độ bắt đầu kết tinh của paraffin: $38,3^{\circ} \mathrm{C}$; Nhiệt độ sản phẩm trên miệng giếng khai thác: $50-70^{\circ} \mathrm{C}$. Thành phần, tính chất đặc trưng của dầu ở mỏ Đại Hùng Nam được thể hiện thông qua Bảng 1 và giản đồ pha tại Hình 2.

\subsection{Mô hình hóa đường ống ngầm vận chuyển dầu tù̀ WHP - DHN về giàn $Đ H$ - 01}

Tuyến ống vận chuyển sản phẩm bão hoà khí từ giàn WHP - DHN về FPU DH - 01 có tổng chiều dài $8800 \mathrm{~m}$ được đặt trên nền cát của đáy biển, chiều sâu của nước biển khu vực này trung bình vào khoảng $110 \mathrm{~m}$. Trên cơ sở các số liệu khảo sát địa hình tuyến đường ống WHP - DHN về FPU DH - 01, profile tuyến ống WHP - DHN cũng có dạng như Hình 3. 
Bảng 1. Thành phần dầu tại mỏ Đại Hùng Nam (Tổng Công ty Thăm dò Khai thác Dầu khí, 2019).

\begin{tabular}{|c|c|c|c|c|}
\hline TT & Thành phần & Mol $(\%)$ & Mol $(w t)$ & Mật độ chất lưu $\left(\mathrm{g} / \mathrm{cm}^{3}\right)$ \\
\hline 1 & N2 & 0,107 & 28,014 & - \\
\hline 2 & CO2 & 1,922 & 44,01 & - \\
\hline 3 & C1 & 47,041 & 16,043 & - \\
\hline 4 & C2 & 6,657 & 30,07 & - \\
\hline 5 & C3 & 4,656 & 44,097 & - \\
\hline 6 & iC4 & 1,305 & 58,124 & - \\
\hline 7 & nC4 & 1,828 & 58,124 & 0,664 \\
\hline 8 & iC5 & 0,924 & 72,151 & 0,738 \\
\hline 19 & nC5 & 0,702 & 72,151 & 0,765 \\
\hline 10 & C6 & 3,042 & 86,178 & 0,835 \\
\hline 11 & C7 & 5,245 & 96 & 107 \\
\hline 12 & C8 & 2,889 & 212,0842 & \\
\hline 13 & C9+ & 23,682 & & \\
\hline
\end{tabular}

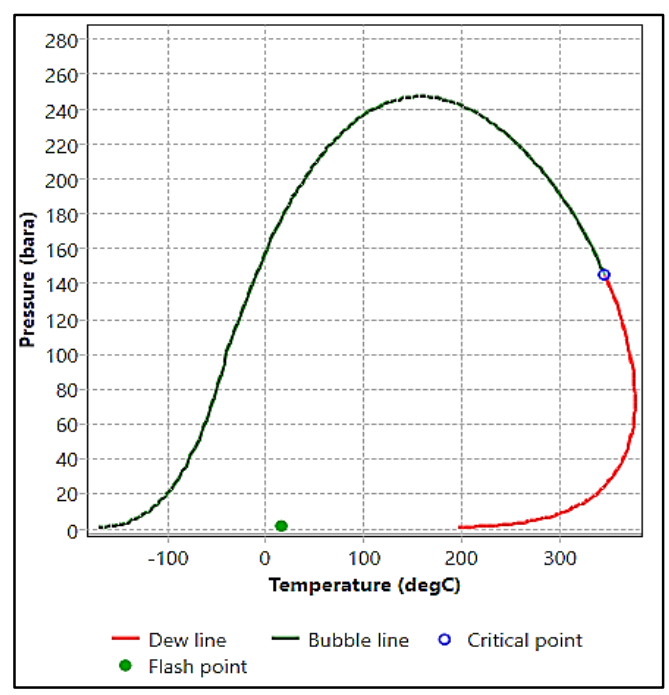

Hình 2. Giản đồ pha dầu khí tại mỏ Đại Hùng Nam.

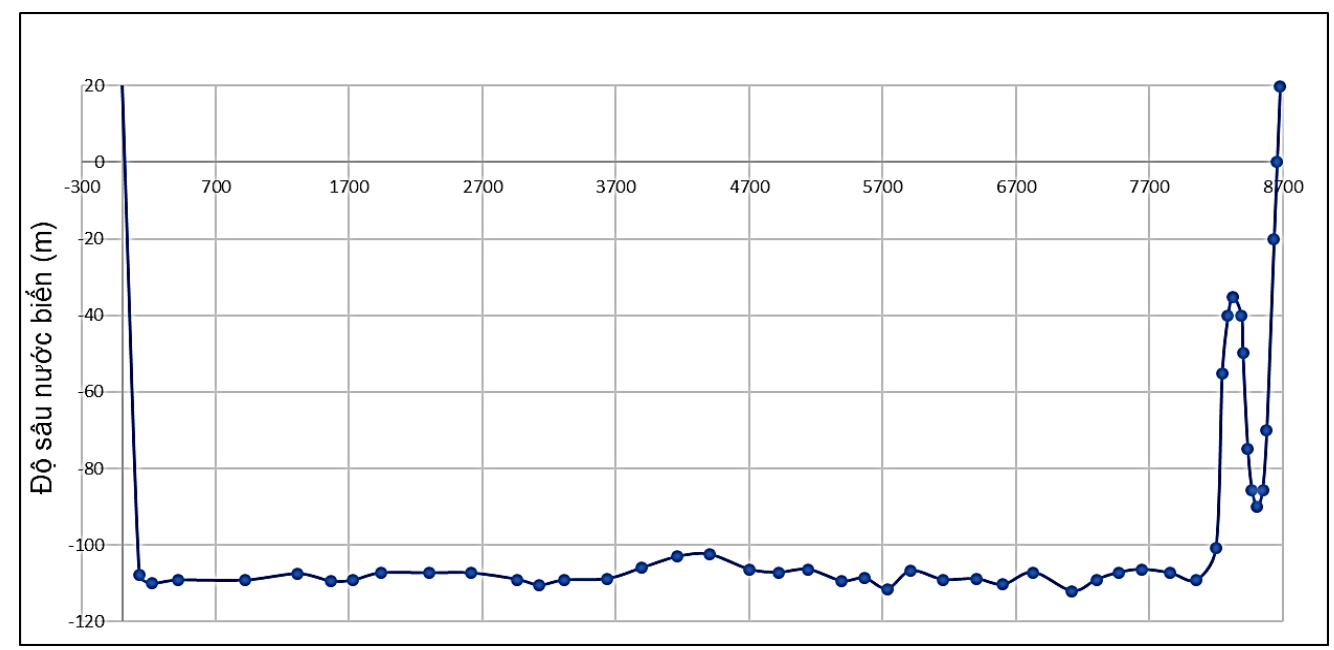

Hình 3. Hình dạng tuyến đường ống vận chuyển sản phẩm tù̀ WHP - DHN về DH - 01. 


\subsection{1.. Xác định đường kính trong của đường ống}

Trong phần này, bài báo trình bày các nghiên cứu nhằm tính toán, lựa chọn đường kính trong và chiều dày lớp cách nhiệt của đường ống dẫn dầu phù hợp nhất cho 2 trường hợp sản lượng lớn nhất và nhỏ nhất (khi suy giảm sản lượng), các thông số lựa chọn phải đảm bảo các yêu cầu: Đường kính nhỏ nhất đảm bảo vận chuyển lưu lượng dầu mong muốn lớn nhất $(18.000$ thùng/ngđ), với tỉ số dầu khí GOR=1.000 SCF/STB; Chiều dày lớp cách nhiệt nhỏ nhất đảm bảo nhiệt độ dầu tại đầu nhận cao hơn nhiệt độ hình thành paraffin khi suy giảm sản lượng $(8.000$ thùng/ngđ); Đánh giá áp suất đầu vào với các tỷ số khí/ dầu khác nhau; Mô hình mô phỏng với 2 trường hợp lưu lượng 8.000 thùng/ngđ (khi suy giảm sản lượng) và 18.000 thùng/ngđ ở chế độ dòng chảy ổn định (Steady State). Trên cơ sở đó, các thông số đầu vào được lựa chọn như Bảng 2.

Chiều dày lớp cách nhiệt ban đầu để chạy mô hình: $35 \mathrm{~mm}$; Tỷ số khí dầu của dầu bão hòa từ WHP - DHN là 1.000 SCF/STB (tương đương 178 $\mathrm{sm}^{3} / \mathrm{sm}^{3}$ ) cho trường hợp đưa phần lớn khí về giàn FPU DH - 01. Yêu cầu cần tính toán lựa chọn đường kính ống nhỏ nhất đảm bảo: Áp suất đầu vào tại WHP - DH2 $\leq 25$ bar; Nhiệt độ về đến FPU $\mathrm{DH}-01 \geq 38^{\circ} \mathrm{C}$. Kết quả chạy mô hình hóa được chỉ ra trong Bảng 3.

Dựa vào các kết quả trong Bảng 3 cho thấy, đường kính tối ưu nhất (nhỏ nhất) được chọn thỏa mãn áp suất tại đầu vào tại WHP - $\mathrm{DHN} \leq 25$ bar có kích thước 12 inch, tương ứng với đường kính trong là 288,84 $\mathrm{mm}$.

\subsubsection{Xác định chiều dày lóp bọc cách nhiệt của} đường ống

Sau khi chọn lựa được kích thước đường ống, bước tiếp theo cần xác định chiều dày lớp cách nhiệt để đảm bảo dầu không bị đóng paraffin trong đường ống do nhiệt độ xuống thấp bởi tác động của nhiệt độ môi trường biển. Lưu lượng để chạy mô hình là lưu lượng thấp nhất tương ứng với giai đoạn giảm sản lượng là 8.000 thùng/ngđ. Tiến hành chạy mô phỏng bằng phần mềm PIPESIM với các chiều dày lớp cách nhiệt lần lượng là $35 \mathrm{~mm}, 45 \mathrm{~mm}$ và $55 \mathrm{~mm}, 65 \mathrm{~mm}$ và 75 $\mathrm{mm}$. Kết quả chạy mô hình hóa được chỉ ra trong Bảng 4.

Bảng 2. Các thông số đầu vào của chương trình.

\begin{tabular}{|c|c|c|c|c|c|c|c|c|}
\hline TT & \begin{tabular}{|c|} 
Đường kính \\
trong của \\
ống $(\mathrm{mm})$ \\
\end{tabular} & \begin{tabular}{|c|} 
Độ \\
nhám \\
$(\mathrm{mm})$
\end{tabular} & $\begin{array}{l}\text { Lưu lượng } \\
\text { (thùng/ngđ) }\end{array}$ & $\begin{array}{c}\text { Nhiệt độ đầu } \\
\text { vào trên WHP - } \\
\text { DHN }\left({ }^{\circ} \mathrm{C}\right)\end{array}$ & $\begin{array}{l}\text { Áp suất lớn nhất } \\
\text { tại đầu vào trên } \\
\text { WHP - DHN (bar) }\end{array}$ & $\begin{array}{l}\text { Áp suất tối } \\
\text { thiểu tại } \\
\text { DH1 (bar) }\end{array}$ & $\begin{array}{c}\text { Tổn thất } \\
\text { áp suất } \\
\text { (bar) }\end{array}$ & $\begin{array}{l}\text { Hệ số truyền } \\
\text { nhiệt } \\
\left(\mathrm{W} / \mathrm{m} \cdot{ }^{\circ} \mathrm{C}\right)\end{array}$ \\
\hline 1 & 193,7 & \multirow{4}{*}{0,028} & \multirow{4}{*}{18.000} & \multirow{4}{*}{60} & \multirow{4}{*}{25} & \multirow{4}{*}{11} & \multirow{4}{*}{0,5} & \multirow{4}{*}{0,135} \\
\hline 2 & 242,82 & & & & & & & \\
\hline 3 & 288,84 & & & & & & & \\
\hline 4 & 317,597 & & & & & & & \\
\hline
\end{tabular}

Bảng 3. Kết quả chạy mô phỏng với các kích thước đường ống khác nhau.

\begin{tabular}{|c|c|c|c|c|c|}
\hline TT & $\begin{array}{c}\text { Đường kính } \\
\text { trong của ống } \\
(\mathrm{mm})\end{array}$ & $\begin{array}{c}\text { Áp suất tại WHP - DHN } \\
\text { (bar) }\end{array}$ & $\begin{array}{c}\text { Nhiệt độ tại WHP - } \\
\text { DHN }\left({ }^{\circ} \mathrm{C}\right)\end{array}$ & $\begin{array}{c}\text { Áp suất tại FPU DH - } \\
\text { 01 (bar) }\end{array}$ & $\begin{array}{c}\text { Nhiệt độ tại FPU } \\
\text { DH - 01 }\left({ }^{\circ} \mathrm{C}\right)\end{array}$ \\
\hline 1 & 193,7 & 46,5 & 60 & 11,5 & 41,16 \\
\hline 2 & 242,82 & 28 & 60 & 11,5 & 41,05 \\
\hline 3 & 288,84 & 20,5 & 60 & 11,5 & 40,35 \\
\hline 4 & 317,597 & 17,7 & 60 & 11,5 & 39,7 \\
\hline
\end{tabular}

Bảng 4. Kết quả tính toán nhiệt độ với các chiều dày lớp cách nhiệt khác nhau.

\begin{tabular}{|c|c|c|c|c|c|}
\hline TT & Chiều dày cách nhiệt $(\mathrm{mm})$ & Nhiệt độ vào $\left({ }^{\circ} \mathrm{C}\right)$ & Nhiệt độ ra $\left({ }^{\circ} \mathrm{C}\right)$ & Áp suất vào (bar) & Áp suất ra (bar) \\
\hline 1 & 35 & 60 & 28.8 & 14.8 & 11.49 \\
\hline 2 & 45 & 60 & 32.5 & 14.8 & 11.56 \\
\hline 3 & 55 & 60 & 35.4 & 14.8 & 11.56 \\
\hline 4 & 65 & 60 & 37.5 & 14.8 & 11.54 \\
\hline 5 & 75 & 60 & 39.4 & 14.75 & 11.54 \\
\hline
\end{tabular}


Từ bảng tổng hợp ở trên (Bảng 4) có thể thấy, để vận chuyển dầu từ WHP - DHN về FPU DH - 01 trong trường hợp suy giảm sản lượng (8000 thùng/ngđ) đảm bảo nhiệt độ dầu $\geq 38^{\circ} \mathrm{C}$ thì chiều dày lớp cách nhiệt tối thiểu là $65 \mathrm{~mm}$.

\section{3. Đánh giá hiện tượng tạo slug theo địa hình và múcc độ tác động đến các thông số vận chuyển dầu trong đường ống}

Trong quá trình di chuyển trong ống do thay đổi địa hình đặc biệt tại các đoạn ống đứng. Với các kịch bản được đưa ra về sản lượng là: 8.000 , $10.000, \quad 12.000,14.000,16.000,18.000$ thùng/ngđ, trong phần này nhóm tác giả sẽ đánh giá tác động của địa hình đến các thông số liên quan quá trình vận chuyển dọc trong đường ống.

2.3.1. Tương quan giũa áp suất và nhiệt độ

- Trường hợp lưu lượng 8.000 thùng/ngđ (Hình 4).

- Trường hợp lưu lượng 10.000 thùng/ngđ (Hình 5).

- Trường hợp lưu lượng 12.000 thùng/ngđ (Hình 6).

- Trường hợp lưu lượng 14.000 thùng/ngđ (Hình 7).

- Trường hợp lưu lượng 16.000 thùng/ngđ (Hình 8).

- Trường hợp lưu lượng 18.000 thùng/ngđ (Hình 9).

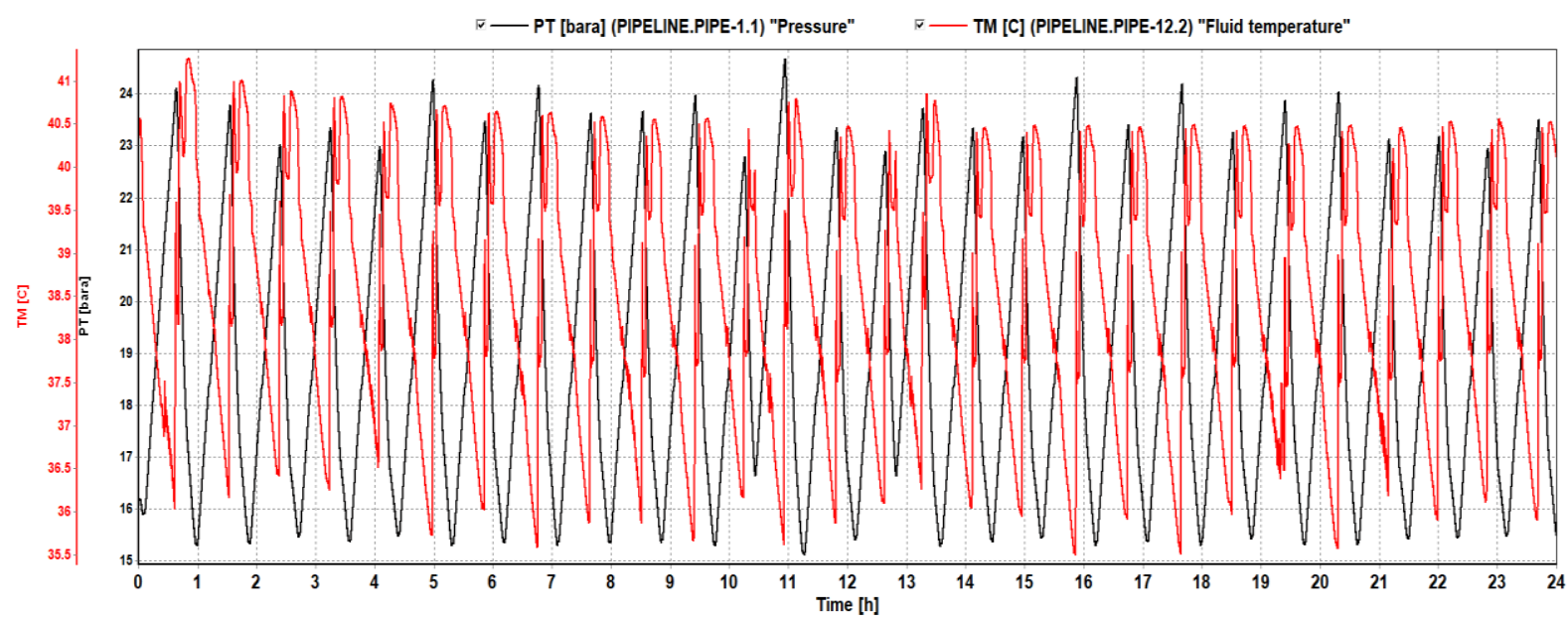

File: Slugging Study.tpl

Hình 4. Biến thiên áp suất và nhiệt độ trong 24 giờ với sản lượng 8.000 thùng/ngđ.

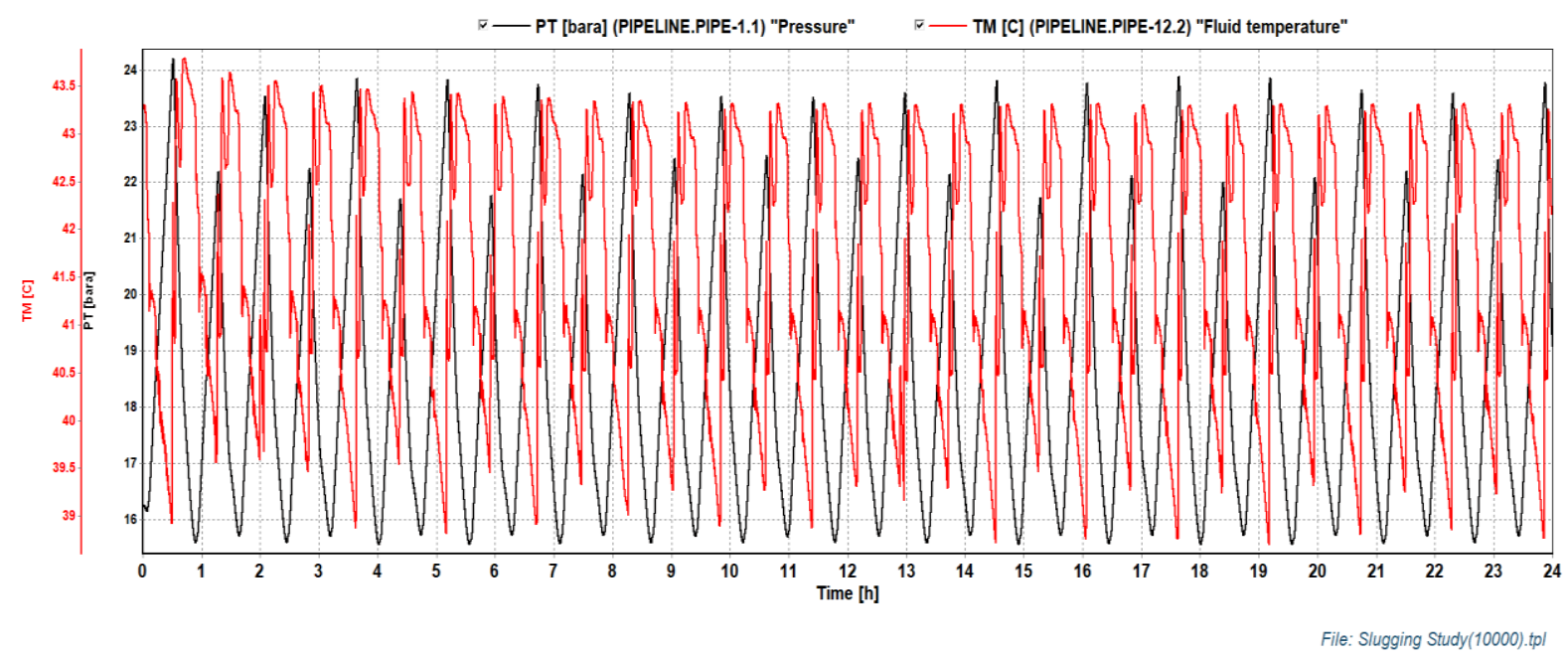

Hình 5. Biến thiên áp suất và nhiệt độ trong 24 giờ với sản lượng 10.000 thùng/ngđ. 


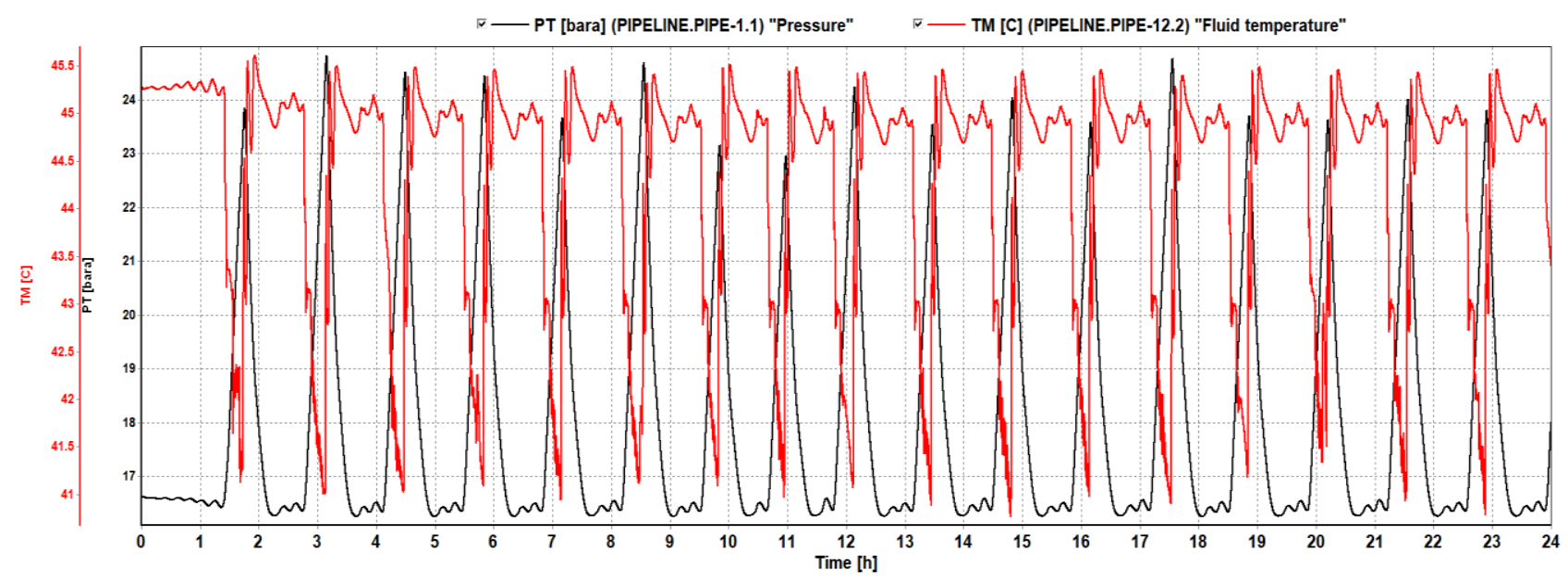

Hình 6. Biến thiên áp suất và nhiệt độ trong 24 giờ với sản lượng 12.000 thùng/ngđ

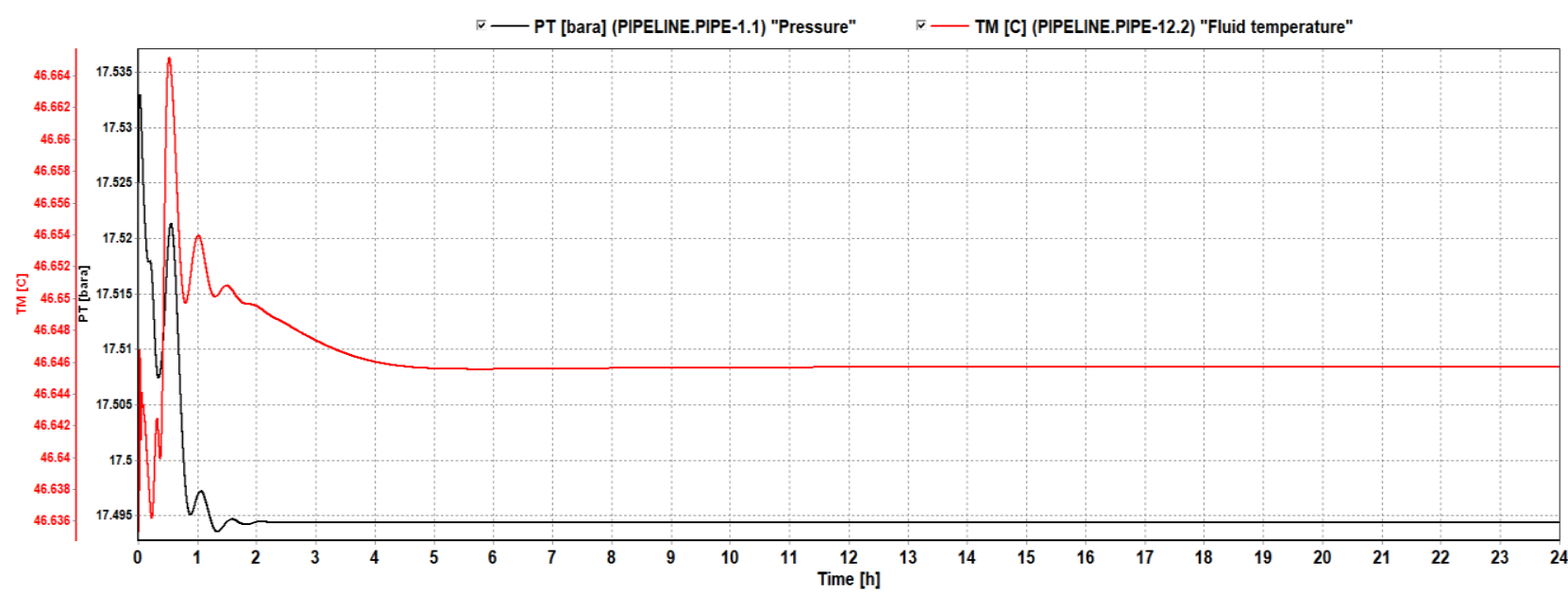

File: Slugging Study(14000).tpl

Hình 7. Biến thiên áp suất và nhiệt độ trong 24 giờ với sản lượng 14.000 thùng/ngđ.

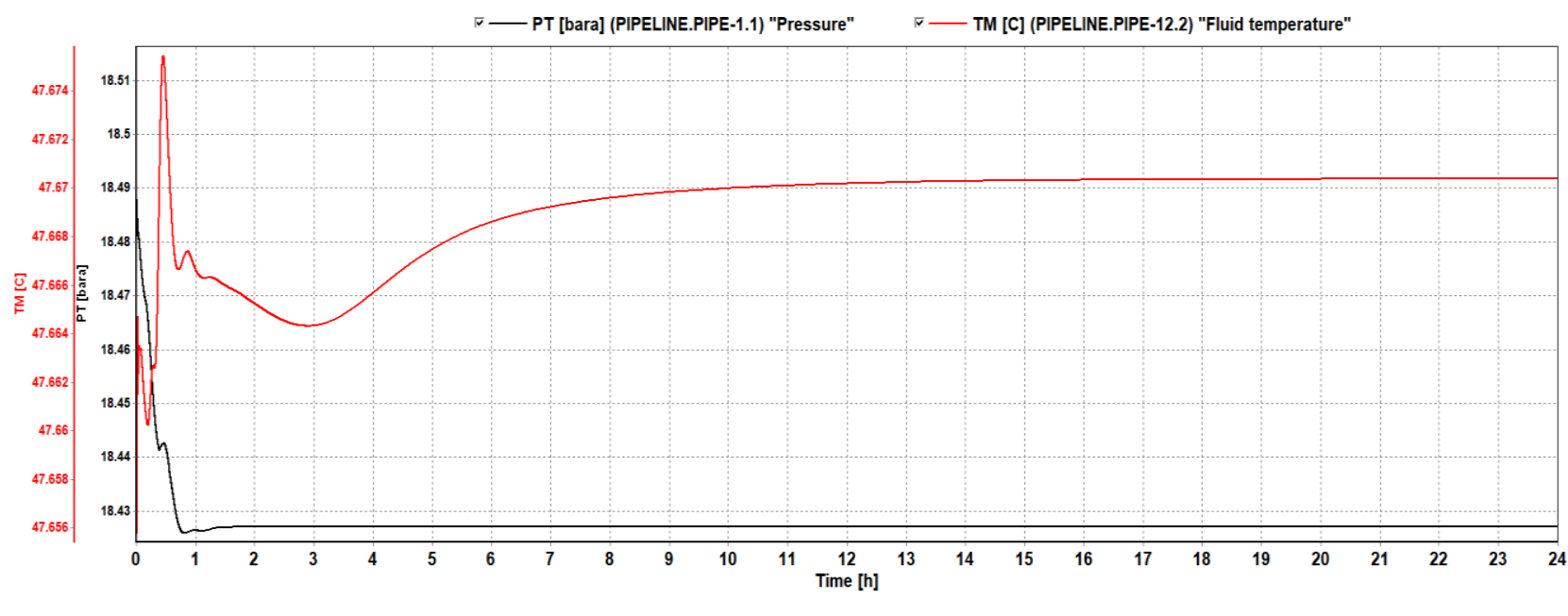

Hình 8. Biến thiên áp suất và nhiệt độ trong 24 giờ với sản lượng 16.000 thùng/ngđ. 


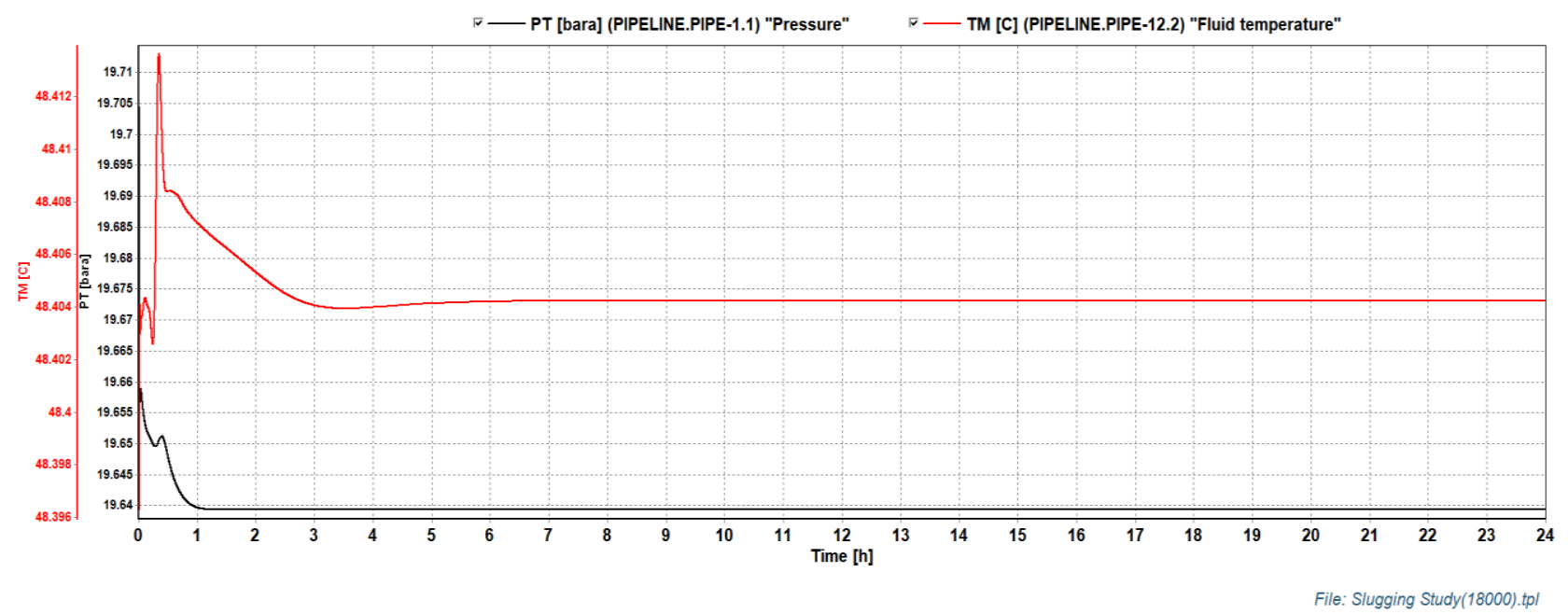

Hình 9. Biến thiên áp suất và nhiệt độ trong 24 giờ với sản lượng 18.000 thùng/ngđ.

Nhiệt độ sản phẩm tại bình tách trên giàn DHN dự kiến là $60^{\circ} \mathrm{C}$, nhiệt độ nước tại đáy biển là $16 \div 18^{\circ} \mathrm{C}$, nhiệt độ không khí là $26^{\circ} \mathrm{C}$. Với điều kiện ở trên và hệ số cách nhiệt và chiều dày lớp cách nhiệt đã chọn, nhiệt độ tại đầu nhận của DH1 là 29,40 C. Các thông số về nhiệt độ và áp suất theo các kịch bản khác nhau được trình bày như trong Bảng 5.

\subsubsection{Tương quan vận tốc chất lỏng dọc thành ống tùy theo địa hình}

Các kết quả nghiên cứu chỉ ra rằng vận tốc chất lỏng liên tục thay đổi theo địa hình của đường ống, thậm chí xảy ra hiện tượng chất lỏng bị rơi do tác động của lực trọng trường khi di chuyển trong đoạn ống đứng với lưu lượng 8.000 và 10.000 thùng/ngđ. Chất lỏng trong ống di chuyển với vận tốc cao nhất trên đường ống đứng tại giàn WHP DHN hướng xuống đáy biển. Vận tốc dòng chảy thấp nhất tại đường ống đứng phía đầu nhận trên giàn FPU DH - 01. Vận tốc trung bình trong các kịch bản sản lượng trên đều >1, dòng chảy không bị gián đoạn. Chi tiết về các kết quả nghiên cứu được thể hiện như trong Bảng 6.

\subsection{Thảo luận kết quả}

Từ kết quả chạy mô hình tính toán đường kính ống, chiều dày lớp cách nhiệt và kết quả tính toán nhiệt thuỷ lực đường ống vận chuyển dầu dưới dạng bão hòa khí từ WHP - DHN về giàn FPU DH 01, nhận thấy rằng: Đường kính tối ưu để đảm bảo vận chuyển 18000 thùng dầu/ngđ với GOR 1.000 SCF/STB từ WHP - DHN về giàn FPU DH - 01 là 12 inch, tổng chiều dài $8.800 \mathrm{~m}$. Chiều dày lớp cách nhiệt đảm bảo từ $65 \mathrm{~mm}$ trở lên (hệ số cách nhiệt $0,135 \mathrm{~W} / \mathrm{m}^{-}{ }^{\circ} \mathrm{C}$ ) để đảm bảo khả năng an toàn trong quá trình vận chuyển dầu từ WHP - DHN về DH1, ngay cả trong trường hợp sản lượng giảm xuống mức 8.000 thùng/ngđ. Lưu lượng vận chuyển thấp thì tổn hao áp suất trung bình trong quá trình vận chuyển cũng thấp. Tuy nhiên biên độ dao động áp suất là rất lớn, thông số làm việc của hệ thống không ổn định, ảnh hưởng xấu đến hệ thống công nghệ. Lưu lượng càng thấp thì tổn thất nhiệt độ càng lớn trong cùng đường kính ống vận chuyển (Bảng 5). Sự ổn định của dòng chảy phụ thuộc nhiều vào địa hình đặc biệt là tại các ống đứng khi lưu lượng thấp, trong trường hợp này là dưới 8.000 thùng/ngđ. Để cải thiện dòng chảy trong quá trình vận chuyển với lưu lượng thấp (trong giai đoạn First Oil), nhằm hạn chế ảnh hưởng xấu đến hệ thống thiết bị có thể áp dụng các biện pháp sau: Điều chỉnh tiết diện đầu cuối đường ống (Topside Choking); Bơm bổ sung thêm nước tại đầu vào để gia tăng lưu lượng và vận tốc của chất lưu, ... Trong trường hợp này cần phải bơm thêm hóa phẩm giảm nhiệt độ đông đặc để chống paraffin trong đường ống.

\section{Kết luận}

Tuyến đường ống kết nối giàn WHP - DHN về giàn FPU DH - 01 đang trong quá trình xây dựng kế hoạch phát triển. Nghiên cứu đảm bảo dòng chảy để tìm ra giải pháp tối ưu cho quá trình thu gom vận chuyển sản phẩm là thực sự cần thiết và có ý nghĩa khoa học, đáp ứng yêu cầu của thực tế 
Bảng 5. Tổng hợp thông số áp suất, nhiệt độ theo các kịch bản sản lượng.

\begin{tabular}{|c|c|c|c|c|c|c|c|}
\hline TT & $\begin{array}{c}\text { Lư lượng } \\
\text { (thùng/ ngđ) }\end{array}$ & $\begin{array}{c}\text { Áp suất tại } \\
\text { DHN (bar) }\end{array}$ & $\begin{array}{c}\text { Áp suất tại FPU } \\
\text { DH - 01 (bar) }\end{array}$ & $\begin{array}{c}\text { Nhiệt độ tại } \\
\text { DHN }\left({ }^{\circ} \mathrm{C}\right)\end{array}$ & $\begin{array}{c}\text { Nhiệt độ tại FPU } \\
\text { DH - 01 }\left({ }^{\circ} \mathrm{C}\right)\end{array}$ & $\begin{array}{c}\text { Tôn thất áp } \\
\text { suất (bar) }\end{array}$ & $\begin{array}{c}\text { Tôn thất } \\
\text { nhiệt độ }\left({ }^{\circ} \mathrm{C}\right)\end{array}$ \\
\hline 1 & 8.000 & 16,19 & 11,50 & 59,64 & 40,36 & 4,69 & 19,28 \\
\hline 2 & 10.000 & 16,24 & 11,50 & 59,70 & 43,24 & 4,74 & 16,47 \\
\hline 3 & 12.000 & 16,62 & 11,51 & 59,75 & 45,26 & 5,11 & 14,49 \\
\hline 4 & 14.000 & 17,54 & 11,51 & 59,78 & 46,64 & 6,03 & 13,14 \\
\hline 5 & 16.000 & 18,50 & 11,51 & 59,80 & 47,66 & 6,99 & 12,14 \\
\hline 6 & 18.000 & 19,66 & 11,51 & 59,82 & 48,40 & 8,14 & 11,42 \\
\hline
\end{tabular}

Bảng 6. Vận tốc dòng chảy trong ống theo các kịch bản lưu lượng khác nhau.

\begin{tabular}{|c|c|c|c|c|c|c|c|}
\hline \multirow{2}{*}{ TT } & \multirow{2}{*}{ Vận tốc dòng chảy trung bình (m/s) } & \multicolumn{5}{|c|}{ Lưu lương vận chuyển (thùng/ngđ) } \\
\cline { 3 - 8 } & & 8.000 & 10.000 & 12.000 & 14.000 & 16.000 & 18.000 \\
\hline 1 & Cao nhất & 7,48 & 7,99 & 8,43 & 8,81 & 9,06 & 8,05 \\
\hline 2 & Thấp nhất & 0,72 & 1,02 & 1,32 & 1,64 & 1,97 & 2,24 \\
\hline 3 & Tại DH1 & 1,04 & 1,50 & 2,02 & 2,58 & 3,16 & 3,63 \\
\hline 4 & Hiện tượng drop & Có & Có & Không & Không & Không & Không \\
\hline
\end{tabular}

hiện nay về khai thác dầu tại khu vực mỏ Đại Hùng. Các kết quả nghiên cứu đã chỉ ra rằng, dầu khai thác tại khu vực DHN là dầu có hàm lượng paraffin và độ nhớt cao, nhiệt độ đông đặc của dầu là $30^{\circ} \mathrm{C}$. Nhiệt độ bắt đầu kết tinh của paraffin (Wax Apearance Temparature, WAT), được xác định ở mức $38,3^{\circ} \mathrm{C}$. Chính vì vậy trong trường hợp shutdown hệ thống, nguy cơ dầu đông đặc trong đường ống là rất cao.

Trong quá trình khai thác, khi lưu lượng giảm xuống mức dưới 8000 thùng/ngđ cần phải kết hợp giải pháp về bơm thêm hóa phẩm giảm nhiệt độ đông đặc để chống paraffin trong đường ống. Với chế độ khai thác 18000 thùng dầu/ngđ, đường kính tối ưu nhất được lựa chọn thỏa mãn áp suất tại đầu vào tại WHP - DHN $\leq 25$ bar có kích thước 12 inch. Trong quá trình vận chuyển, có thể xuất hiện hiện tượng chất lỏng bị rơi do tác động của trọng lực khi di chuyển trong đoạn ống đứng đối với trường hợp lưu lượng 8.000 và 10.000 thùng/ngđ. Chất lỏng trong ống di chuyển với vận tốc cao nhất tại đường ống đứng tại giàn WHP DHN hướng xuống đáy biển. Vận tốc dòng chảy thấp nhất tại đường ống đứng phía đầu nhận trên giàn FPU DH - 01. Ngoài ra, để đảm bảo khả năng an toàn trong quá trình vận chuyển dầu từ WHP DHN về FPU DH - 01, thậm chí ngay cả khi sản lượng giảm xuống mức 8.000 thùng/ngđ, chiều dày lớp cách nhiệt tối thiểu là $65 \mathrm{~mm}$ (hệ số cách nhiệt $0,135 \mathrm{~W} / \mathrm{m}-{ }^{\circ} \mathrm{C}$ ). Với chiều dày tối thiểu như vậy, dòng sản phẩm về tới giàn FPU DH1 có nhiệt độ luôn đạt mức cao hơn nhiệt độ bắt đầu kết tinh của paraffin.

\section{Tài liệu tham khảo}

Aiyejna, A., Chakrabarti, D. P., Pilgrim, A., Sastry, M K. S., (2011). Wax formation in Oil Pipelines: A critical Review. International Journal of Multiphase Flow 37, 671 - 694.

Burger, E. D., Perkins, T. K, Striegler, J. H., (1981). Studies of Wax Deposition in the Trans Alaska Pipeline. Journal of Petroleum Technology. 1075 - 1086.

Nguyễn Thúc Kháng, Từ Thành Nghĩa, Tống Cảnh Sơn, Phạm Bá Hiền, Phạm Thành Vinh, Nguyễn Hoài Vũ, (2016). Công nghệ xử lý và vận chuyển dầu nhiều paraffin ở thềm lục địa Việt Nam. Nhà xuất bản Khoa học Kỹ thuật - Hà Nội.

Nguyễn Văn Thịnh, Nguyễn Hải An, Nguyễn Thanh Hải, (2018). Nghiên cứu giải pháp đảm bảo dòng chảy cho đường ống vận chuyển dầu từ giàn WHP - DH2 tới giàn FPU - DH1 mỏ Đại Hùng. Tạp chí Khoa học Kỹ thuật Mỏ - Địa chất, 59(4). 52 - 62.

Tổng Công ty Thăm dò Khai thác Dầu khí, (2017). Daily Prduction. PVEP - POC.

Tổng Công ty Thăm dò Khai thác Dầu khí, (2019). Báo cáo cập nhật Kế hoạch phát triển mỏ Đại Hùng và Lô 15 - 1a. Tài liệu nội bộ Công ty PVEP - POC. 